\title{
Two Concepts of Freedom in Criminal Jurisprudence
}

\author{
Roni Rosenberg* \\ Ono Academic College, Israel
}

\begin{abstract}
The goal of this essay is to identify and discuss two aspects of liberty by examining the distinction between act and omission in criminal jurisprudence. Criminal law makes a significant distinction between harmful actions and harmful omissions and, consequently, between killing and letting die. Any act that causes death is grounds for a homicide conviction -- subject, of course, to the existence of the other elements necessary for establishing criminal liability, such as causation and mens rea. However, liability for death by omission is subject to the additional identification of a duty to act. In other words, the defendant will be liable only if we can identify such a duty and show that the breach of this duty resulted in the victim's death. This distinction between act and omission is rooted in an ethical perspective, in which we instinctively see a difference between actively behaving in a manner that causes harm and passively failing to prevent such harm. Nevertheless, since the beginning of the 1960s, there has been a significant movement to attack and criticize this moral distinction. This critique impacts upon the legal sphere as well, since if the moral distinction between act and omission is not obvious, the legal distinction cannot be clear-cut either. This lack of clarity has led to many attempts to lay a logical foundation for the intuitive understanding that there is indeed a legal distinction between act and omission.

This essay focuses on two principles that reflect different aspects of human liberty which are reflected in criminal jurisprudence. The first is liberal liberty, and the second which I propose, is personal autonomy. While both relate to liberty of the individual, they approach it from different angles, and this difference in perspective results in different definitions of act and omission in criminal jurisprudence.
\end{abstract}

\section{CONTENTS}

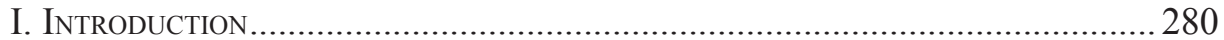

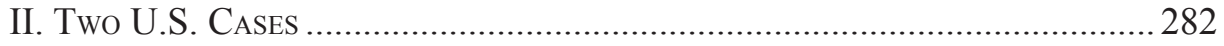

III. The Liberty Rationale...................................................................... 283

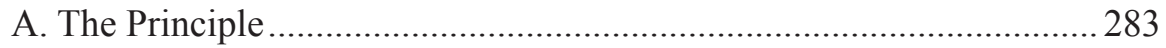

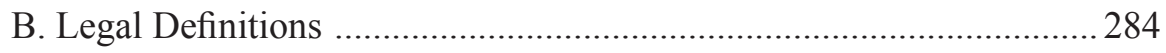

* Roni Rosenberg is a Senior Lecturer at the Faculty of Law, Ono Academic College, Israel, and a scholar at the Taubenschlag Institute of Criminal Law, Faculty of Law, Tel Aviv University. 
IV. The Personal Autonomy Rationale .................................................. 285

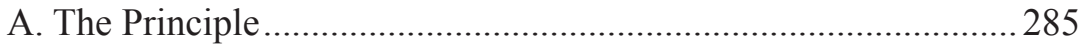

B. The Rawlsian Social Contract..................................................28 287

C. Comparison With the Liberty Rationale ....................................... 290

D. Loss of Personal Autonomy - Legal Definition........................... 291

E. Criticism of the Personal Autonomy Analysis .............................2296

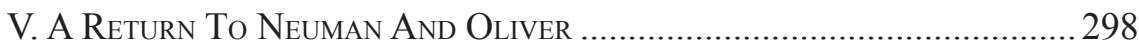

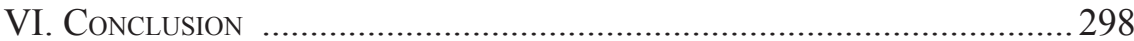

\section{INTRODUCTION}

The goal of this essay is to identify and discuss two aspects of liberty by examining the distinction between act and omission in criminal jurisprudence. Criminal law makes a significant distinction between harmful actions and harmful omissions and, consequently, between killing and letting die. Any act that causes death is grounds for a homicide conviction - subject, of course, to the existence of the other elements necessary for establishing criminal liability, such as causation and mens rea. However, liability for death by omission is subject to the additional identification of a duty to act. In other words, the defendant will be liable only if we can identify such a duty and show that the breach of this duty resulted in the victim's death. This distinction is further reflected in the proposed Model Penal Code, which states in section 2.01(3)(b) that liability for an offense may not be based on an omission unless a duty to perform the omitted act is otherwise imposed by law.

This distinction between act and omission is rooted in an ethical perspective, in which we instinctively see a difference between actively behaving in a manner that causes harm and passively failing to prevent such harm. Nevertheless, since the beginning of the $1960 \mathrm{~s}$, there has been a significant movement to attack and criticize this moral distinction. ${ }^{1}$ The primary question is whether there is, in fact,

\footnotetext{
For the ethical perspective, see O.H. Green, Killing and Letting Die, 17 APQ (1980) 195; Philippa Foot, Killing and Letting Die, in Killing And Letting Die (Bonnie Steinbock and Alastair Norcross eds., 1994) 283; Jeff McMahan, Killing, Letting Die, and Withdrawing Aid, in Killing and Letting Die (Bonnie Steinbock and Alastair Norcross eds., 1994) 383; P.J. Fitzgerald, Acting and Refraining, 37 AnALYsis 133 (1967); Tracy L. Isaacs, Moral Theory, Action Theory, Killing and Letting Die, 32 APQ 355 (1995); Jonathan Bennett, Whatever the Consequences, in Killing and Letting Die (Bonnie Steinbock and Alastair Norcross eds., 1994) 167; Bruce Russell, Presumption, Intrinsic Relevance, and Equivalence, 4 J. of Med. \& Phil. 263 (1979); James Rachels, Killing and Starving to Death, 54 PHIL. 159 (1979); James Rachels, Active and Passive Euthanasia, in KiLling ANd LetTing Die 112 (Bonnie Steinbock and Alastair Norcross ed., 1994); John Harris, The Marxist Conception of Violence, 3 Phil. \& Pub. Aff. 192; Shelly Kagan, The Limits of Morality 83-127 (1991); Michael Tooley, An Irrelevant Consideration: Killing Versus Letting Die, in Killing and Letting Die 103 (Bonnie Steinbock and Alastair
} 
a moral distinction between causing harm and letting harm happen; more specifically, is there such a distinction between killing and letting die? Furthermore, if, in fact, one can make such a moral distinction, what is the moral imperative behind it? According to these critics, when the two scenarios are otherwise equal in all respects - that is, the intent, the expense of preventing death, and the result are all the same in both cases, there is no moral ground for drawing a distinction between killing and letting die.

Obviously, this critique impacts upon the legal sphere as well, since if the moral distinction between act and omission is not obvious, the legal distinction cannot be clear-cut either. This lack of clarity has led to many attempts to lay a logical foundation for the intuitive understanding that there is indeed a legal distinction between act and omission, yet it seems that creating this clear distinction is easier said than done. ${ }^{2}$

Among the various rationales that have been presented for this distinction, this essay focuses on two principles that reflect different aspects of human liberty that are reflected in criminal jurisprudence. The first is liberal liberty, and the second is personal autonomy. While both relate to liberty of the individual, they approach it from different angles, and this difference in perspective results in different definitions of act and omission in criminal jurisprudence.

The essay is structured as follows: part 2 describes two U.S. court decisions, involving manslaughter conviction in cases of omission, that emphasize the distinction between action and omission. Part 3 presents the liberal liberty principle and explains how it provides a reason for this distinction in the criminal context. The chapter goes on to specify the definitions of act and omission that are consistent with this rationale and concludes by discussing difficulties that arise in the context of this analysis. Part 4 introduces a new rationale for the distinction between act and omission, that of personal autonomy. Part 4 continues to compare the two rationales and their respective implications for the distinction between killing and letting die. Part 5 applies these two rationales, respectively, to the analysis of the U.S. decisions presented in Part 2.

While the distinction between act and omission is general in nature, this article focuses on the distinction between killing and letting die, since that is the primary

Norcross ed., 1994); Tracy L. Isaacs, Moral Theory, Action Theory, Killing and Letting Die, 32 APQ 355 (1995).

For the legal perspective, see George Fletcher, On the Moral Irrelevance of Bodily Movements, 142 U. Pa. L. Rev. 1443 (1994); George P. Fletcher, Rethinking Criminal Law 593-602 (1978); George P. Fletcher, Basic Concepts of Criminal Law 59-70 (1998); Joel Feinberg, Harm to Others 159-181 (1984); Arthur Leavens, A Causation Approach to Criminal Omissions, 76 CAL. L. Rev. 547 (1998); Michael S. Moore, Act and Crime: The Philosophy of Action and Its Implications for Criminal LaW 25-26 (1993); Michael S. Moore, More on Act and Crime, 142 U. PA. L. Rev. 1749 (1994); F. M. Kamm, Action, Omission, and the Stringency of Duties, 142 U. PA. L. REv. 1493 (1994); Leo Katz, Proximate Cause in Michael Moore's Act and Crime, 142 U. PA. L. REV. 1513 (1994).

2 For example, Honore states, "My reason for discussing the acts and omissions doctrine is that, though law is strongly committed to it, lawyers have not been very successful in finding a rationale for it.” Tony Honore, Responsibility and Fault 41(1999). 
example used in philosophical and legal discourse to elucidate the distinction between act and omission.

\section{Two U.S. CASES}

In State of Wisconsin v. Dale Neuman, ${ }^{3}$ an eleven-year-old girl died as a result of her diabetes because her parents chose to treat her by prayer rather than seek the medical care that, apparently, would have saved her life. The parents continued to pray and not to treat their daughter with conventional medicine as the girl's condition deteriorated and even when she eventually lost consciousness. The parents were convicted of manslaughter because of their failure to procure medical care.

The court held that:

Although the second-degree reckless homicide statute, Wis. Stat. Section 940.06(1) does not include specific language criminalizing an omission, the parties agree, as do we, that an actor may be criminally liable for a failure to act if the actor has a legal duty to act. $^{4}$

In this case, the court found, the parents had a duty to provide appropriate medical care and not to rely on prayer in a situation where there was a medical threat to the child. Thus, had there been no such duty to care for their daughter through conventional medicine (as the parents argued), they would have been acquitted.

In People v. Carol Ann Oliver, ${ }^{5}$ the decedent met the defendant in a bar. $\mathrm{He}$ escorted her home and entered her bathroom to inject himself with heroin, using a spoon provided by the defendant. Consequently, the decedent fell to the floor unconscious. The defendant observed what had occurred and left the house after requesting her daughter to remove the decedent from the house. The next day, he was found dead of an overdose.

The defendant was convicted of involuntary manslaughter under Pen Code 192(b). She argued in her defense that she could not be convicted because there was no duty incumbent upon her to care for the decedent under law since there was no relationship between them. The court disregarded this argument and held that while there is not generally any duty to save a stranger, here, where the decedent had been invited into defendant's home and went into the bathroom after receiving a spoon from her, the risk to his life was heightened, and therefore defendant had a duty to call for medical assistance in order to save him. ${ }^{6}$ In this case as well, it is apparent that had there been no duty to act she would not have been convicted simply because she had the ability to save the decedent by summoning medical assistance.

These two cases are but two examples of U.S. case law, in which many have been convicted of homicide in instances of omissions. However, these cases

\footnotetext{
State of Wisconsin v. Dale Neuman 348 Wis. 2d 455 (2013)

Id. at 94 .

People v. Carol Ann Oliver 210 Cal. App. 3d. 139 (1989).

Id. at 149 .
} 
illustrate that, as opposed to instances that involve acts, where any act can be the basis for a conviction (assuming causation and intent), cases of omission require identification of a duty to act. This duty can originate in explicit legal provision or in a relationship between the victim and the defendant, but without such duty there will be no conviction.

The question, then, is what rationale distinguishes between act and omission with regard to the existence of a duty to act? Why can someone be convicted for an omission that cases harm only where a duty to act has been identified? This distinction is not a given, particularly considering the many scholars that contend that there is no ethical distinction between act and omission.

\section{The LiBerTy RATIONALE}

\section{A. THE PRINCIPLE}

One of the principal theories behind the distinction between act and omission is rooted in the value of personal liberty. ${ }^{7}$ According to this theory, the prohibition against a harmful act does not cause significant loss of personal liberty since all that is required of a person is to refrain from acting. However, a prohibition against a harmful omission does cause significant loss of liberty since it requires the individual to stop whatever she is doing in order to prevent harm from befalling another person. If people were liable for omission even in the absence of a specific duty to act, they would be forced to drop everything and act at a moment's notice, at any time. Since the legal system must allow people to maintain a routine without being forced to stop and go out on random rescue missions, criminal law maintains that liability for omission exists only if a duty to act can be specifically identified. ${ }^{8}$

In this vein, let us assume that John, who lives in Joe's neighborhood, is faced with life-threatening danger. Joe knows this. If Joe were liable even without having a duty to act, he would be forced to drop everything in order to help John since not doing so would risk liability for voluntary and negligent manslaughter.

\footnotetext{
See A.P. Simester \& G.R. Sullivan, Criminal Law: Theory and Doctrine 61-70 (2000); David Ormerod, Smith and Hogan's, Criminal Law (13th edition) 65 (2011); A.P. Simester, Why Omissions Are Special, 1 Leg. Theory 311, 333-35 (1995).

8 Simester, $i d$. A different rationale is sometimes presented in the context of the liberty theory. Some contend that criminal law limits crimes of omission as they restrict personal liberty more than classifying particular acts as criminal. The contention is that prohibiting omission allows an individual to perform a particular act, but it prevents him from doing multiple other ones. However, prohibiting a particular act limits only that act itself and does not prevent the performance of multiple other ones. Critics of this theory contend that it is inaccurate to state that criminalizing omission causes more loss of liberty than crimes of action. The issue of loss of personal liberty relates to the person who is the object of the crime and to his preferences. For example, the prohibition against smoking does not affect a person who has no interest in smoking, but it severely affects a person who is a chain smoker. The fact that the latter can sing or dance instead of smoking does not prevent the loss of personal liberty.
} 
In cases of omission, then, the purpose of requiring a duty to act is to limit the number of scenarios in which an individual must act to prevent harm from befalling others. This limits the individual's loss of liberty and allows him to maintain his normal routine, with minimal interference.

In this context, anything that imposes a duty to act (whether under criminal or civil law) can serve as a basis for conviction of a result crime such as manslaughter because the legislature's decision to impose such a duty indicates that it has determined that the consideration of liberty in the case at hand is set aside. Once liberty is not to be taken into consideration, there is no longer any basis to distinguish between act and omission where they result in identical harm. This is relevant to an analysis of the cases presented above, as will be elaborated upon in Part IV below.

\section{B. LEGAL DEFINITIONS}

According to the liberty theory, the accepted test for defining act and omission is bodily movement. By this test, a muscle twitch that causes harm is classified as an act, while the lack of such a movement is classified as omission. ${ }^{9}$ More specifically, a muscle twitch that causes death is classified as a killing, while the lack of such a movement is classified as a letting die.

The bodily movement test is consistent with the liberty theory: a prohibition against an act (a bodily movement) does not cause significant loss of liberty since the protagonist maintains multiple other avenues of action. On the other hand, a prohibition against omission, which is classified as non-action, does in fact cause loss of liberty as such a prohibition requires the individual to perform certain acts, which, when they recur on a regular or semi-regular basis, prevent her from maintaining a regular routine. If a person is subject to a general obligation to prevent harm, then each time that she becomes aware of a possibly harmful event, she must act to prevent it.

Since a person cannot be in two places, or do two things, at once, she must almost always abandon her routine in order to prevent the harmful event. When such events occur relatively frequently, a person becomes hard-pressed to maintain a normal lifestyle. However, a prohibition against actively causing a certain outcome is different. When one is faced with the option to actively cause a prohibited result, and is forced to choose an alternative mode of action, the fact that a choice is involved means that the loss of liberty is minimal.

In order to complete the picture, it should be noted that the issue of classification as act or omission is independent of the manner in which the act is "expressed." For example, in a case in which a father does not feed his son for a certain period of time, and this leads to the son's death, we would say that the father starved his son. The word "starved" implies an act. Nevertheless, since starving the son did not actually require any act at all, this is in fact an omission. Therefore, the father is liable only because in this particular case there is a duty to act, and not because starving his son is considered an act.

The liberty theory has several aspects that make it imperfect for our purposes. First, the liberty theory is more relevant to crimes of recklessness or negligence. If omission in these crimes did not require a duty to act, people would be liable in

$9 \quad$ Simester \& Sullivan, supra note 7, at 70. 
any event in which they did not assist someone in need. These events are relatively frequent (as we require real or potential knowledge of the elements of the crime), and creating liability for them would cause severe loss of liberty. However, in cases that require intent, this issue is almost nonexistent since liability does not arise unless the person intended for the prohibited result to take place (and cases such as these are, by nature, limited in number). Since criminal law distinguishes between act and omission without considering mens rea, it follows that this distinction cannot be founded on the liberty theory alone.

Furthermore, following the liberty theory alone would, theoretically, lead to the conclusion that a person should not be convicted of manslaughter in situations where her liberty would be lost if she refrained from active killing. Thus, if abstaining from killing would cause loss of liberty or negatively affect one's ability to make a living, then, according to the liberty theory, it would be incorrect to convict of manslaughter since in this particular scenario the prohibition against killing causes significant loss of liberty. ${ }^{10}$ In this instance, the individual's obligation not to kill should be less absolute. Legally, however, this is obviously not the case. The legal obligation not to kill a person actively does not become less acute in proportion to the individual's loss of personal liberty.

The bodily movement test also does not completely lend itself to distinguishing between act and omission. Theoretically, conviction in cases involving bodily movement may still require a duty to act. Consider the following two cases:

"Movement" - John shoots at Joe (who is wearing body armor and would not be injured), and Joe moves to avoid the bullet. The bullet hits Jane and kills her.

According to the bodily movement test, Joe's movement would be classified as killing since it caused Jane's death. Nevertheless, his act is seemingly more accurately defined as a letting die, and, therefore, Joe would be liable only if we could identify a duty to stand in one place and not move.

"Freezing to death" - Joe is about to freeze to death. In order to survive, he tries to enter John's house. John blocks Joe by locking the door. Joe dies.

Even if we assume that Joe would have survived if John had not locked his door, there appear to be no grounds for convicting John of manslaughter. This scenario appears to be a case of failure to rescue rather than one of homicide.

Considering the difficulties in applying the liberty rationale to certain situations, it may be helpful to look at the entire issue from a new and different perspective. While the approach suggested in Part III also revolves around infringement upon human liberty, it does so from a different starting point.

\section{The Personal Autonomy Rationale}

\section{A. THE PRINCIPLE}

Perhaps the distinction between killing and letting die is rooted in the different values that lie at the core of each prohibition. The underlying premise of the liberal liberty theory is that the interests and values behind the prohibitions are similar. The

10 See KaGAN, supra note 1, at 92-94. 
assumption is that in drowning Joe and in not rescuing Joe, John is disregarding the same core value, Joe's life. Is this really the case, however? Perhaps the values at the root of the prohibition against killing are broader and more substantial than those at the root of the prohibition against letting die, and this is what distinguishes the two prohibitions.

In order to examine the interests and values at the core of these prohibitions, we must ask two preliminary questions:

1. What would happen if the prohibition against killing did not exist?

2. What would happen if there were a prohibition against killing (and it were enforced) but there were no prohibition against letting die?

The answers to these two questions can clarify what the reality would be without each prohibition, providing us deeper insight into the purpose of each.

It is likely that without a prohibition against killing, we would be forced to live our lives in constant fear of life-threatening dangers. This fear would cause a significant loss of our basic sense of security, which in turn would lead to a real loss of personal autonomy. People would then be hard-pressed to maximize their personal development as fear would force them to be constantly on the defensive. In this context, Hobbes' words regarding the natural condition are particularly relevant:
And from this diffidence of one another, there is no way for any man to secure himselfe, so reasonable, as Anticipation; that is, by force, or wiles, to master the persons of all men he can, so long, till he see no other power great enough to endanger him...
Whatsoever therefore is consequent to a time of Warre, where every man is Enemy to every man; the same is consequent to the time, wherein men live without other security, than what their own strength, and their own invention shall furnish them withall. In such condition, there is no place for Industry; because the fruit thereof is uncertain; and consequently no Culture of the Earth; no Navigation, nor use of the commodities that may be imported by Sea; no commodious Building; no Instruments of moving, and removing such things as require much force; no Knowledge of the face of the Earth; no account of Time; no Arts; no Letters; no Society; and which is worst of all, continuall feare, and danger of violent death; And the life of man, solitary, poore, nasty, brutish, and short. ${ }^{11}$

According to Hobbes, a reality in which any person is permitted to kill any other person is untenable. There is no humaneness, no culture, no creativity, and, worst of all, a person is forced to live in constant fear of death. It is important to note, in this regard, that this theory does not require that everyone would try to kill everyone else. Even if only part of the population tries to kill another part, every person would still live in constant fear of being killed. Furthermore, even if we are not sure whether or not people would actually try and kill each other, the element of fear

11 Thomas Hobbes, Leviathan or The Matter, Forme, \& Power of a Common-Wealth Ecclesiasticall and Civill 95-97 (Oxford at the Clarendon Press ed., 1952). 
itself (drawn from the knowledge that there is no prohibition against killing) would significantly infringe upon people's personal autonomy. ${ }^{12}$

Robert Nozick describes a society lacking laws prohibiting killing, assault, rape, etc. in the following manner:

A system that allowed assaults to take place... would lead to apprehensive people, afraid of assault, sudden attack, and harm...to avoid such general apprehension and fear, these acts are prohibited and made punishable. ${ }^{13}$

However, the absence of a prohibition against letting die would not lead to the same apprehension. Such a reality may not be optimal, but people certainly would not all be living in constant fear of death (or violence). Human culture would still exist. People would have to beware of dangerous situations, but this is more of an individual concern than a societal one - people would have to take individual responsibility and not place themselves in situations of undue risk.

The differences in the answers to the two questions highlight the differences in the values at the core of each prohibition. The purpose of the prohibition against killing is to protect interests and values much more basic and critical to social norms than the prohibition against letting die. The purpose of the prohibition against killing is to allow individuals to live purposeful lives and maintain personal autonomy without being constantly afraid of losing this ability. When viewed this way, the prohibition against killing is one of the most basic elements of personal autonomy. On the other hand, although the prohibition against letting die may serve to enhance personal autonomy, it is not fundamental to it. ${ }^{14}$

While it may be the case that not every act of homicide has the same detrimental effect on our sense of personal security, nonetheless, killing is still more severe than letting die, as the severity of the act is measured against the severity of the prohibition, and the severity of the prohibition is measured against the interests that it is intended to protect. ${ }^{15}$ In order to further explore the significance of the distinction indicated by the personal autonomy analysis, we turn to Rawls' theory of social contract.

\section{B. The RaWlsian Social Contract}

The personal autonomy rationale can be based, among others, upon Rawls's theory of social contract.

See Gregory S. Kavka, Hobbesian Moral and Political Theory 81-82 (1999).

Robert Nozick, Anarchy, State and Utopia 66 (1974).

14 In this context, it is important to note that although the prohibition against letting die does enhance personal and societal autonomy in some respects, as people know that when necessary they will be rescued, in other respects it actually limits such autonomy since it forces people to be prepared to perform an act of rescue at any given time.

15 The distinction between killing and letting die is just one example (though perhaps the primary one) of the general difference between doing harm and allowing it. Any injurious act is a more serious transgression than causing injury by omission since the prohibition against actively causing injury is a more significant safeguard of personal autonomy than the prohibition against causing injury by omission. Similarly, actively causing damage to personal property creates a greater loss of personal autonomy than causing damage by omission. 
In his book "A Theory of Justice," Rawls presents a theory that purports to serve as a basis for the building blocks of national government. ${ }^{16}$ Rawls assumes that in each society there are both shared and conflicting interests. Shared interests stem from the realization that cooperation is preferable to each individual acting alone. Conflicting interests are rooted in each individual's concern with the societal distribution of rights and obligations ${ }^{17}$ For this reason, says Rawls, it is necessary to create several principles to allow for the just distribution of rights and obligations among individuals as well as the proper distribution of resources. These principles are the rules of justice of basic societal institutions.

Rawls uses the social contract to discover and justify the principles that serve society's basic institutions. ${ }^{18}$ These are the fundamental principles for distribution of rights, obligations and resources among the members of society that free and rational people, concerned with furthering their own interests, would accept in an initial position of equality, or the original position. ${ }^{19}$ Rawls emphasizes that this is not a real contract between particular people, but rather an intellectual exercise designed to determine which principles would be accepted by people in the original position..$^{20}$ People who are in the "initial position of equality" do not know their social position and financial status. They do not know if they are sharp or obtuse, rich or poor, and so forth. ${ }^{21}$ In a situation in which an individual does not know his true position, there is complete equality. This is why Rawls theorizes that laws that are created in the original position are fair. ${ }^{22}$

Rawls suggests that people in the original position would agree on two principles: ${ }^{23}$

1. Each person is to have an equal right to the most extensive scheme of basic liberties.

2. Social and economic inequalities are to be arranged so that they are both reasonably expected to be to everyone's advantage, including society's weakest elements.

Rawls states that the first principle takes priority over the second as the economic advantage does not justify loss of liberty. Liberties can only be compromised when they conflict with other liberties. ${ }^{24}$ The liberties that Rawls discusses are political liberty (the right to vote and to hold public office); freedom of speech and assembly; liberty of conscience and freedom of thought; and freedom of the person, which includes freedom from psychological oppression, physical assault and dismemberment. ${ }^{25}$

John Rawls, A Theory Of Justice (rev. ed., 1999).

Id. at 4 .

Id. at 10 .

Id.

Id. at $11,14$.

Id.

Id. at 17 .

$I d$. at 53 .

Id. at. 53-54. For a critique of this position, see H.L.A. Hart, Rawls on Liberty and Priority, 40 U. ChI. L. Rev. 534-55 (1973).

25 RawLS, supra note 16, at 53. 
Rawls' idea that people in the original position would agree to these principles can be related to the distinction between killing and letting die. As already discussed, the prohibition against killing prevents the individual's life from being wrought with fear. This fear can be translated into a general loss of Rawls' basic liberties. There is no political liberty, no freedom of speech, no freedom of thought and obviously no freedom from psychological oppression and physical assault. It is clear, then, that in order to preserve these liberties, individuals in the original position would agree to the prohibition against killing.

Nickel makes a similar argument:

Creating an effective system of protections of security rights through the criminal law is one of the most important things that can be done to make possible the enjoyment of other liberty below. If those who would invade people's liberties and rights are unrestrained in their ability to threaten death, harm, violence, and loss of property, few if any liberties can be enjoyed. Security rights, like due process rights, are essential building blocks for a system of liberty. ${ }^{26}$

However, preservation of these liberties is not dependent on a rule obligating rescue of others from danger. Such a rule has no bearing on political liberty, freedom of speech, freedom of thought and freedom from psychological oppression and physical assault.

This does not mean that people in the original position would not agree to a rule requiring rescue in certain situations, only that, even if accepted, such a rule would be much more limited and minor than the prohibition against killing. Rawls himself suggests that people in the original position would agree to a rule requiring rescue, as it would improve people's quality of life even absent the need for actual assistance.

A sufficient ground for adopting this duty is its pervasive effect on the quality of everyday life the public knowledge that we are living in a society in which we can depend upon others to come to our assistance in difficult circumstances is itself of great value...the primary value of the principle is not measured by the help we actually receive but rather by the sense of confidence and trust in other men's good intentions and the knowledge that they are there if we need them. ${ }^{27}$

Rawls' argument in favor of a duty to rescue can assist us in better understanding the prohibition against killing. Everyone would agree to the prohibition against killing as it has great effect on our quality of life. The knowledge that no one will harm us is very valuable. Imagine society in general, and each individual in particular, without such a prohibition. People would live in constant fear without the ability to do anything to alleviate it.

As mentioned above, some killings do not infringe upon the prohibition's protected interests; thus, perhaps not every killing is truly different from a letting die. According to the social contract theory, however, we do not examine each specific case. The severity of the act must be assessed based on the principle that would have

26 James W. Nickel, Rethinking Rawls's Theory of Liberty and Rights, 69 CHI.-Kent. L. Rev. 763, 768 (1994).

27 RawLs, supra note 16, at 297-98. 
been agreed to in the social contract, the contract agreed to in the original position of equality. The basic principle that would be generally accepted is the prohibition against killing, and not the rule requiring rescue, as the interests protected by the former are broader and weightier than those protected by the latter.

Under the personal autonomy rationale, the duty to act, in cases of omission, does not mitigate the loss of liberty or replace the need for direct cause and effect; rather it rectifies the omission's relative moral inferiority. This moral inferiority is reflected in the distinctive core values that are at the root of the prohibitions against killing and letting die.

Nonetheless, a person may experience a significant loss of personal autonomy if she knows that in certain situations she will not receive assistance. There are times when an individual becomes embroiled in a dangerous situation through no fault of her own, such as in cases of illness or natural disaster. Loss of autonomy may also result from the person withdrawing from certain activities out of fear that she will not receive assistance when needed. This is why society appoints certain "agents" whose responsibility it is to provide security to those who are in harmful situations. These agents are charged with providing stability and security: doctors to treat illness, lifeguards to prevent drowning, parents to monitor children, etc. These agents provide a vital service as they allow society and its members to realize their autonomy.

If we were to do away with the duty to rescue, even with respect to agents such as police, parents or doctors, personal autonomy would be greatly compromised by the realization that certain things are completely out of our control. This could have the effect of severely hindering societal development. The breach of this duty, then, can sometimes approximate the loss of autonomy caused by an act.

\section{Comparison With the Liberty Rationale}

Both rationales afford a preeminent value to individual liberty and the individual's ability to conduct his life in a reasonable manner. However, there are several fundamental differences. Under the liberal liberty principle, both the prohibition against active killing and that against letting die protect the same interest, human life. The only reason for distinguishing between the two, then, is because if the legal system were to convict people for omissions with no requirement that there be a duty to act, human liberty would be infringed upon in that people would have to go at the drop of a hat to rescue others. That is, the distinction between killing and letting die is intended to preserve individual liberty.

On the other hand, under the personal autonomy principle, the prohibition against killing protects a broader and more significant interest than does that against letting die. The prohibition against killing is directed to the autonomy of man, since without such a prohibition a person would live in constant fear of being killed, while a prohibition against letting die may broaden individual's autonomy but is not a prerequisite for it. Thus, the essence of this distinction in criminal jurisprudence is not in order to preserve liberty; rather, it reflects the fact that killing is a greater infringement on personal autonomy than letting die. In other words, the distinction in and of itself, reflects the fact that the prohibition against killing is a prerequisite for autonomy while that against letting die is not.

Moreover, liberty under the liberty rationale differs from liberty discussed in this chapter. Under liberty analysis, making this distinction is intended to protect the 
individual's ability to live a routine life without interference from a legislator who obligates him to save others on a constant basis. However, such an infringement upon liberty does not infringe upon the dignity of man as man and does not infringe upon his very humanness. Thus, were there no such distinction, while there would be significant challenges for the individual who is attempting to live his normal life, it would not prevent him from living a meaningful life. There would still be some "islands" where he could exercise his liberty; for example when it was clear that there is no one around in need of rescue or when the individual does not have the ability to save someone else. In addition, while it might, indeed, be difficult to live a normal life, it would be possible to save lives of others, and this ability to save others has significance in that it gives a person an opportunity to exercise his abilities in such instances.

On the other hand, personal autonomy does not focus on human liberty, the right to live without interference by a legislator that requires him to save others. This analysis focuses on a person's ability to live a life free of constant fear and with a basic sense of security, without constant threats from others. This is the primary liberty that the personal autonomy rationale protects, since this infringement significantly impacts the very humanity and dignity of a person. Moreover, without a basic sense of security a person's ability to plan his life would be seriously compromised. The only way to protect this aspect of liberty is via prohibiting killing, as without such a prohibition a person lives in constant fear. In contrast, absence of a prohibition against letting die would still enable a person to live a reasonable life, with personal autonomy and a sense of security, such that this prohibition is much less significant. Consequently, we do not convict of such an omission without identifying a duty to act.

\section{Loss of Personal Autonomy - LeGal Definition}

As mentioned above, the definition of act and omission used must reflect the rationale of a threat to personal autonomy. Therefore, killing must be defined such that the relevant prohibition enables life without fear. Letting die, on the other hand, must be defined such that the relevant prohibition reflects the values of assistance and broad personal autonomy. In my opinion, in order to provide for a basic sense of security without fear, the prohibition against killing must cover intrusion into the individual's protected space. Intrusion into the life of another is caused largely by the creation of a risk or removal of certain defenses relating to the victim. The definition of killing, then, is sometimes also connected to the question of ownership - i.e., who is the owner of the defense that was removed. The general concept is to create a protected space, a secure area that may not be intruded upon. If a person dies as a result of such an intrusion, it would be classified as a killing. We would not require, then, the identification of a duty to act in order to convict the defendant. However, if a person dies other than as a result of an intrusion into her protected space, the event would be classified as a letting die. There are, therefore, certain situations that involve bodily movement that are not considered killing as the movement did not breach a protected space, while there are other situations that do not involve bodily movement but are still considered killing as they do involve such a breach.

In this context, ownership of the defense is not a matter of a right to personal property as an ideal in and of itself. Removal of a defense belonging to the victim should not be classified as a killing because of the loss of personal property. Rather, it is the fact that individuals protect themselves largely via their bodies and property 
that causes removal of a defense belonging to the victim to infringe upon the interests that are at the immediate root of the prohibition against killing. ${ }^{28}$

\section{$i$ The Implications of Ownership of the Defense}

a. Who owns the defense: the agent or the victim?

A basic assumption is that when the agent creates the risk, the act is classified as a killing. By drowning Joe in the sea, John caused Joe's death and therefore John's act is a killing. This scenario involves a breach of the individual's protected space by directly harming his person..$^{29}$ On the other hand, when John sees Joe drowning and does not jump to his rescue, John did not create the risk and breach Joe's protected space (even if he had a direct causal effect on Joe's death), and therefore John's conduct is a letting die.

Nevertheless, the issue of the removal of the defense, along with its ownership, bears further analysis.

The following two scenarios will help clarify my approach:

(A) Mid-ocean escape: John is about to die at sea. Suddenly, he notices Joe standing on the deck of his boat, watching. John swims over to the boat in order to save himself. Joe is not interested in saving John and sails the boat away. John dies. ${ }^{30}$

(B) Movement: John shoots at Joe (who is wearing body armor and would not be injured), and Joe moves to avoid the bullet. The bullet hits Jane and kills her.

According to the personal autonomy theory, neither scenario is a killing, even though both involve bodily movement. This is because in both scenarios Joe removed a defense that belonged to him and not to the victim. In the first scenario, Joe moved his boat, which itself served as a defense against John's death. Similarly, in the second scenario Joe moved his own body, which at the time served as a defense against the airborne bullet.

A slight modification of the scenarios will hone the moral significance of this point:

(C) Mid-ocean escape 1: Joe stands on John's boat and pilots the boat to shore. John dies.

(D) Movement 1: Joe places Jane so that she will be hit by John's bullet.

28 The context in which ownership is used here is independent of the libertarian concept of property as sovereignty. Libertarianism demands that personal property be preserved in order to maximize negative liberty, which in turn is required for "human flourishing." In addition, my ideas here do not depend on the notion of property as defining the individual, as part of the "self." Ownership here is relevant because it serves to protect the protected space from intrusion. Such protection is needed not against tyrannical government, but against other individuals. According to my theory, the protected space allows people to live without fear in order to carry on their normal lives.

29 Obviously, that creation of the risk may not be directly connected to the individual's physical person. For example, planting a bomb that causes mass death. Nonetheless, even a scenario such as this involves intrusion into the individual's protected space, even if the person who planted the bomb did so in his own home.

30 For a parallel scenario, see the scenario Freezing to Death in Part 2 above. 
The latter two scenarios should be classified as killings as here Joe prevents the victims from utilizing their own defenses.

The difference between scenarios A and B as opposed to C and D is ownership of the defense. In scenarios $\mathrm{A}$ and $\mathrm{B}$, the defense belongs to the agent, while in scenarios $\mathrm{C}$ and $\mathrm{D}$ it belongs to the victim. Ownership of the defense is not a mere technicality. Removing a defense that belongs to the agent is not considered a breach of the victim's protected space, while removing a defense that belongs to the victim is. Intruding on this space means loss of personal and social autonomy and merits a more severe conviction. ${ }^{31}$

It is possible to demonstrate certain cases in which the agent damaged or removed a resource that belonged to the victim, causing the victim to die, and yet the agent is still not guilty of manslaughter. This, however, would be due to lack of legal causation. In such cases, the defense's removal is critical to the end result, but the agent is not convicted of manslaughter because of his circumstantial distance from the actual harm. Imagine a case in which A steals money from certain people who had intended to donate it to the hospital in order to purchase drugs and life support machines. The theft prevented the donation and several patients died as a result. A is unlikely to be convicted of manslaughter due to the lack of legal causation as a result of circumstantial distance from the effect. The distinction between removing a defense belonging to the victim and removing one that belongs to the agent is valid only in cases where we can identify legal cause and effect.

\section{b. When the defense belongs to a third party, or to no one at all}

What is the rule when the defense does not belong to the agent or to the victim, but to a third party or to no one at all? Will the agent's removal of the defense be classified as a killing or as a letting die? Will we require a duty to act?

When the defense belongs to a third party, we must distinguish between whether the third party allowed the victim to use the defense or not. If the defense was at the victim's disposal, it is tantamount to actually belonging to the victim, and the agent's act would be classified as a killing. If Joe disconnects John from a hospitalowned ventilator, Joe's act would be classified as a killing since he removed a

31 Because the loss of personal autonomy theory is based on the concept that an individual's person and resources create a protected space in which he can live in basic security, it follows that we should distinguish between resources that define a protected space and those that do not. Based on this distinction, there may be times where the agent removes a protective defense belonging to him, and the case would still be classified as killing. For example: A jumps from the roof of a building, with the knowledge that $\mathrm{B}$ has a safety net spread at the bottom of the building that will save A if he falls directly on it. $\mathrm{B}$ moves the net, and A dies. In this case, even though the net belongs to B, we may not require a duty to act in order to convict $\mathrm{B}$ of killing. This is because it is possible that not every resource belonging to the agent defines his own protected space. Under these particular circumstances, it is possible that the net does not define the individual's personal protected space, and therefore its removal constitutes killing. On the other hand, a person's house does constitute his personal protected space, and therefore A locking his own door so that B freezes to death outside would be classified as letting die and require a duty to act for a conviction. In other words, a hypothetical social contract defines when certain resources constitute personal protected space in order to ensure life without fear. There are resources that will always be considered protected space (such as a person's home) and there are others that will constitute such a space only in specific cases (such as the net). 
defense that was provided to John by the hospital. However, if the third-party owner did not grant the victim use of the defense, the situation becomes somewhat ambiguous. How would we classify a case in which Joe pilots Bill's boat to shore, while leaving John to drown?

The answer apparently lies in the agent's need for the defense. The greater the agent's need for the defense, the less his act is considered a killing. When the victim's need for the defense is greater than the agent's, the victim has a "need right" to the defense. ${ }^{32}$ Removal of the defense in such a case would constitute a breach of the victim's protected space. However, when both the agent and the victim have an acute need for the defense, they would both qualify as having a "need right." In such a case, both parties have an equal claim to the defense and there is no breach of protected space (since both parties have equal rights to the defense, there is no protected space to begin with). ${ }^{33}$

The scenario in which the defense does not belong to anyone appears more complicated. For example, how would we classify a case in which the agent pilots away a boat that does not belong to anyone? On the one hand, perhaps the answer here too depends on each party's need for the defense. However, intuitively we may also suggest that the answer here is different. Imagine the following scenario:

Death from disease: John will die from a certain disease unless he undergoes a particular, and extremely expensive, medical procedure. John, much to his delight, becomes aware of a treasure hidden outside his house that will allow him to finance his procedure. Joe also becomes aware of the treasure and runs to dig it up before John can get to it. Joe then proceeds to spend the treasure on his own needs. As a result, John does not have the procedure and dies.

In this scenario, both parties have equal rights to the treasure, though John has the greater need. Nevertheless, Joe's act should still be classified as a letting die. In order to convict Joe of manslaughter or murder we would need to identify a duty to act, i.e. a specific duty obligating Joe to rescue John. However, if John had been the owner of the treasure, then Joe's act would be classified as a killing and he could be convicted of manslaughter or murder regardless of the existence of a duty to act. ${ }^{34}$

Thus, one can distinguish between situations in which the defense belongs to a

32 The term is coined by Kai Draper in Rights and the Doctrine of Doing and Allowing, 33 PPA 253, 271 (2005). Draper himself uses the term to suggest that even if the defense belongs to the agent, when the victim has a "need right" the defense's removal would be considered killing.

33 Draper suggests a scenario in which both parties have equal rights to the defense. Two people are on a sinking ship, but there is only one life vest that belongs to neither one of them. Each party obviously has a right to use the life vest and if one had been holding it, he would not be considered the other party's killer. However, if neither party was holding the vest and one party reached it before the other, the taking of the vest from the one who reached it first, would be considered an act of killing. Draper supra note 32, at 274.

34 I think it important to reiterate here that the emphasis is not on ownership. I am not suggesting that the treasure belonging to John makes the case a more severe one. I am proposing that in the framework of a social contract, we would agree that these rules are necessary to allow for life without fear. Such a contract would initially prohibit acts of killing that are brought about by harming our person or property. After that, the contract would prohibit acts of killing brought about by causing loss of third-party resources (such as removing a defense belonging to a third party). Only then would the contract prohibit letting die, meaning not providing assistance or removing a defense belonging to the agent himself. 
third party and the defense is ownerless. When the defense belongs to a third party, classifying the act depends on the "need right" of the agent and the victim. However, when the defense does not belong to anyone, the classification is independent of "need right."

This distinction between killing and letting die based on the question of ownership of the defense is supported by several authors.

This appears to be Frances Kamm's approach as well:

Essentially, removing a defense against a potential cause of death - this could be a cause that had at one time already threatened the person or something entirely new - is a killing if the person who dies was not dependent for the defense on the person who terminates it. If an agent terminates aid and so allows a potential cause of death actually to kill someone, but it is aid that the agent himself was providing, or aid that belongs to the agent, then we have a letting die (this disjunctive set of conditions is meant to include cases in which A takes what is B's to help $C$, and $B$ then removes $i t) .{ }^{35}$

That is, when the defense belongs to the agent, its removal is a letting die. When the defense belongs to the victim, its removal is a killing.

\section{c. Separating Conjoined Twins - Act or Omission?}

The personal autonomy theory is reinforced by a UK ruling regarding the separation of conjoined twins. Jodie and Mary were born conjoined twins. Each girl had her own brain, heart, kidneys, arms, legs and other organs. However, Mary's heart and liver received blood and oxygen from Jodie. Without Jodie, Mary would have died at birth.

The case presented to the court was as follows. If the girls were not separated they would both die within several months as Jodie's heart was not strong enough to support both of them. If the girls were separated, Jodie would survive and Mary would die immediately. The twins' parents could not agree to the procedure as it would mean killing one girl to save the other.

During the hearing, the question was posed as to whether separating the twins would be tantamount to murdering Mary. Among other issues, the court debated whether separating the twins was considered act or omission. Some suggested that separation was equivalent to removing life support (as Jodie provided Mary with blood and oxygen), and thus, according to the Bland precedent, considered omission. ${ }^{36}$

F.M. Kamm, Morality, Mortality: Rights, Duties, and Status 28-29 (1996). The emphasis is mine. Although it is unclear according to McMahan and Kamm what the ruling would be when the agent placed a defense belonging to the victim and subsequently removed it, it is clear that the definition of killing and letting die is based, at least somewhat, on ownership of the defense. See also Judith Jarvis Thomson, Physician - Assisted Suicide: Two Moral Argument, 109 Етнісs 497, 503-504 (1999). According to Thomson, if A provided a defense for B, at A's effort and expense, and then removes the defense, it is considered letting die only so long as A did not undertake to provide B with said defense. If he did so undertake, Thomson would classify this as killing.

36 Airedale NHS Trust v. Bland [1993] AC. 789. 
The court, however, did not accept this comparison. This was because separating the twins required an invasion of Mary's body and not just treatment of Jodie's organs. The invasion of Mary's body turned the instance to act as opposed to omission.

7.7 Act or omission in this case?

I set out earlier (I realise with embarrassment a lot earlier) how this operation would be performed. The first step is to take the scalpel and cut the skin. If it is theoretically possible to cut precisely down the mid-line separating two individual bodies, that is not surgically feasible. Then the doctors have to ascertain which of the organs belong to each child. That is impossible to do without invading Mary's body in the course of that exploration. There follow further acts of separation culminating in the clamping and then severing of the artery. Whether or not the final step is taken within Jodie's body so that Jodie's aorta and not Mary's aorta is assaulted, it seems to me to be utterly fanciful to classify this invasive treatment as an omission in contra-distinction to an act. Johnson J.'s valiant and wholly understandable attempt to do so cannot be supported and although Mr. Whitfield Q.C. did his best, he recognised his difficulty. The operation has, therefore, to be seen as an act of invasion of Mary's bodily integrity and unless consent or approval is given for it, it constitutes an unlawful assault upon her. ${ }^{37}$

In other words, the court explained that it was not a case of omission, not because it involved a bodily movement, but rather because the procedure required an invasion of Mary's body. An invasion of bodily integrity cannot be classified as omission. From the ruling it appears that if it had been possible to separate the twins solely by operating on Jodie's body, then the scenario would have been defined as omission. However, because the procedure involved an invasion of Mary's body it must be defined as act.

\section{E. CRiticism of the Personal Autonomy Analysis}

The personal autonomy theory appears to be based on the assumption that the prohibition against killing prevents people from killing each other, thus preventing fear and the loss of personal autonomy that is a by-product of this fear. This assumption, however, is not indisputable as the opposite may also be true. Why not assume that human nature is inherently good and that the majority of people would not try to kill each other? If this were the case, then even without the prohibition against killing, people would not experience the fear that leads to loss of personal autonomy.

Even if we do not approach Hobbes' extreme natural condition of war of all against all, it is likely that at minimum there will be certain people who will act belligerently toward others. This likelihood creates loss of a basic sense of security and personal autonomy. Furthermore, even if no one actually exercises the ability

37 Re A (children) (conjoined twins: surgical separation) [2000] 4 All E.R. 961, 1003. The emphasis is mine. 
to attack others, it is likely that the uncertainty regarding personal safety will create a general sense of fear. The prohibition against killing mitigates the likelihood of attack by another and thus, at least theoretically, also decreases the fear of such an attack. Fear does not only stem from actuality, but also from the possibility of such an actuality. In this way, the prohibition against killing represents a safeguard of a basic element of our normal existence.

Moreover, irrespective of the dispute regarding basic human nature and what would happen without a prohibition against killing, lawmakers are charged with taking a more conservative approach and must assume the worst. Assuming otherwise would be foolish as the risks in taking a more lenient approach are very high. Therefore, even though it may be unclear what exactly the result would be of not having a prohibition against killing, it is reasonable to assume that certain motivations (hatred, personal gain, survival, etc.) would push people to try and kill each other.

A question that challenges this approach is: Isn't the prohibition against homicide intended to protect physical life in and of itself? If so, what justifies the distinction between killing and letting die? Why shouldn't we convict someone who could have prevented the death of another and failed to do so, since this failure to save infringed upon the protected value of human life (even if it does not affect society's sense of security)?

However, it is not that the liberty rationale is not relevant with regard to distinguishing between act and omission in criminal jurisprudence but that it should be supplemented with the personal autonomy rationale. On the one hand, we desire that people be able to live free from constant fear, while on the other hand, we desire that people be able to live without a constant obligation to interrupt their lives and save others. In order to balance these goals, when the purpose of a prohibition is to enable people to live with a sense of security, considerations of liberty take a backseat. Consequently, even if prohibiting killing does infringe upon liberty, this prohibition is still appropriate because it enables people to live their daily lives free of fear. On the other hand, when the prohibition is not intended to ensure that people will live free of fear, considerations of liberty remain at the fore. Thus, since the prohibition against letting die is not required in order to permit people to live free of fear, we do not choose to require people to save others at a significant cost to their liberty.

In other words, prohibiting active killing enables people to live without constant fear and does not infringe overly much upon personal liberty, so we choose to apply it across the board. However, the prohibition on letting die is not aimed at allowing people to live without fear and significantly infringes upon liberty. Thus, we do not apply cross the board. That is, the consideration of liberty as expressed in the liberty rationale is relevant only because in the absence of the prohibition people would still live without constant fear. If we fail to distinguish between the prohibition that protects society's sense of security (killing) and that which does not do so (letting die), considerations of liberty in and of themselves are not helpful.

Finally, in situations in which a personal sense of security would be significantly infringed upon were their no requirement to rescue, the duty to rescue is much more significant even though it does infringe upon personal liberty. Consequently, it is appropriate to convict of homicide for an omission. 


\section{A Return to Neuman and Oliver}

Applying the two rationales to the cases presented above will achieve the same result in Neuman but different results in Oliver. In Neuman the duty to act originated in the relationship between the defendants and the victim. Under the liberal liberty analysis, the legislator's decision to impose a duty to act on parents determines a priori that considerations of liberty retreat where a daughter is in dire straits. Thus, where the parents breach their legal duty to act, resulting in the death of their daughter, they can be convicted of homicide.

Under the personal autonomy analysis, this case would fall into the category of situations in which there is equal moral weight to active killing. The legal duty attributed to the parents because of the relationship originates both in the fundamental ethical duty of parents vis-a-vis their children and in the fact that the absence of such a duty would infringe significantly upon the child's autonomy. As such, here too the parents can be convicted.

With regard to Oliver, however, there was no relationship between the parties at the outset. The court held that the duty to act originated from the fact that the risk was intensified as a result of the defendant's actions of admitting the decedent into her home and providing him with a spoon to take into the bathroom. In fact, this added risk was minor, and the primary risk was caused by the actions of the decedent himself. Nonetheless, under liberal liberty analysis, the defendant's conviction makes sense, since imposing a duty to act on someone in such a situation does not infringe upon his liberty, as we are dealing with a situation that occurs rarely. That is, curtailing liberty in such situations still allows people in general to lead normal lives.

In contrast, under personal autonomy analysis, the fact that the infringement upon liberty is minor does not suffice. Under this analysis, we must prove that there is a significant duty originating in the relationship between the defendant and the victim (parent/child) or between the victim and the source of danger (lifeguard) or a duty such that the absence thereof infringes significantly upon individual liberty. In Oliver there was no duty of such magnitude; thus, the defendant should not have been convicted.

\section{CONCLUSION}

This article presents two aspects of liberty by analyzing the distinction between act and omission in the context of criminal jurisprudence. Under the liberal liberty rationale, the distinction between act and omission in criminal jurisprudence is necessary to preserve human liberty. In the absence of the requirement to identify a duty to act in order to convict for an omission, people would be forced to act constantly to save lives and would be prevented from living their normal lives. This analysis is consistent with use of the bodily movement test for defining act and omission.

This article proposes a different rationale for the distinction between act and omission, the infringement upon personal autonomy. Under this analysis, the distinction between prohibiting active killing and prohibiting letting die is due to the different interests at the root of these prohibitions. Consideration of the following 
question helps to demonstrate these different interests: What would happen if there were no prohibition against killing, and what would happen if there were a prohibition against killing but not against letting die?

In answer to the first question, in the absence of a prohibition against killing, it is likely that people would live in fear, without a basic sense of security. This fear would cause a loss of personal autonomy, regardless of whether it was realized or not. However, personal autonomy would not be compromised (or minimally so) absent the existence of a prohibition against letting die. This approach conforms to the Hobbesian and Rawlsian theories of social contract. Finally, the article presents a new definition for killing and letting die, one that is independent of the agent's bodily movement.

This personal autonomy analysis, coupled with the classic liberty analysis, allows us to achieve the dual goals of enabling people to live free both from a constant fear of attack and from an imperative to spend their lives on call for rescue missions. At the same time, it refines our process for determining whether or not we require the identification of a duty to act in order to convict for an omission. 